\title{
Produtividade de milho e retorno econômico em sistema integrado de produção com doses de nitrogênio
}

\author{
Maize yield and economic return in integrated production system with doses of nitrogen
}

\author{
Marcos Renan Besen ${ }^{1 *}$, Ricardo Henrique Ribeiro ${ }^{2}$, Marina Goetten ${ }^{3}$, Samuel Luiz Fioreze ${ }^{3}$, Claudia \\ Aparecida Guginski-Piva ${ }^{4}$, Jonatas Thiago Piva ${ }^{5}$
}

\author{
${ }^{1}$ Universidade Estadual de Maringá, Maringá, PR, Brasil. *Autor para correspondência: marcos.besen@hotmail.com. \\ ${ }^{2}$ Universidade Federal do Paraná, Curitiba, PR, Brasil. \\ ${ }^{3}$ Universidade Federal de Santa Catarina, Curitibanos, SC, Brasil. \\ ${ }^{4}$ Universidade do Oeste de Santa Catarina, Campos Novos, SC, Brasil. \\ ${ }^{5}$ Universidade Tecnológica Federal do Paraná, Santa Helena, PR, Brasil.
}

Submissão: 19/11/2018 / Aceite: 10/12/2019

\begin{abstract}
RESUMO
O milho é altamente exigente e responsivo à adubação com nitrogênio $(\mathrm{N})$, estando inserido em vários sistemas produtivos, com destaque recente para os sistemas integrados de produção. Assim, objetivou-se avaliar o efeito de doses de $\mathrm{N}$ sob o milho, bem como o aspecto econômico em sistema integrado. $\mathrm{O}$ delineamento experimental utilizado foi de blocos ao acaso com quatro repetições. Foram avaliadas quatro doses de $\mathrm{N}$ em cobertura $\left(0,40,80\right.$ e $\left.120 \mathrm{~kg} \mathrm{ha}^{-1}\right)$. O milho foi cultivado sob palhada do consórcio de aveia e azevém. Verificou-se que diâmetro do colmo, altura de inserção da espiga, e características da espiga, com exceção do número de fileiras por espiga aumentaram linearmente em função das doses de $\mathrm{N}$, por sua vez, a altura da planta respondeu de forma quadrática até a dose de $81 \mathrm{~kg} \mathrm{ha}^{-1}$ de $\mathrm{N}$. A produtividade aumentou de forma expressiva em função do $\mathrm{N}$, indicando efeito residual da adubação no inverno e elevada eficiência de uso do $\mathrm{N}$ no sistema produtivo. A maior produtividade e lucratividade foram obtidas na dose de $120 \mathrm{~kg} \mathrm{ha}^{-1} \mathrm{~N}$.
\end{abstract}

PALAVRAS-CHAVE: Zea mays L., nitrogênio, plantio direto, efeito residual, rentabilidade.

\begin{abstract}
Maize is highly demanding and responsive to nitrogen $(\mathrm{N})$ fertilization, inserted in several production systems, with the recent highlight for integrated production systems. This study aimed to assess the effect of $\mathrm{N}$ rates on maize, as well as the economic aspect in an integrated production system. The experimental design was a randomized complete block design with four replicates. Four $\mathrm{N}$ rates in topdressing $(0,40$, 80 , and $120 \mathrm{~kg} \mathrm{ha}^{-1}$ ) were assessed. Maize was cultivated under black oat and ryegrass mixed straw. Stem diameter, main ear insertion height, and ear parameters, except for the number of rows per ear, which increased linearly as a function of $\mathrm{N}$ rates, in turn, plant height responded quadratically until $81 \mathrm{~kg} \mathrm{~N}$ $\mathrm{ha}^{-1}$. Grain yield increased significantly as a function of $\mathrm{N}$, indicating a residual effect of winter fertilization and high $\mathrm{N}$ use efficiency in the production system. The highest grain yield and profitability were obtained at the rate of $120 \mathrm{~kg} \mathrm{~N} \mathrm{ha}^{-1}$.
\end{abstract}

KEYWORDS: Zea mays L., nitrogen, no-tillage, residual effect, profit.

\section{INTRODUÇÃO}

O uso de fertilizantes nitrogenados na cultura do milho é imprescindível para garantir a produção, sendo um dos fatores mais limitantes para o aumento da produtividade da cultura. O nitrogênio (N) é o nutriente absorvido em maior quantidade pelo milho, sendo constituinte essencial das proteínas e interfere diretamente no processo fotossintético, contudo é o insumo que mais onera o custo de produção da cultura (SILVA et al. 2005a). O uso de $\mathrm{N}$ na cultura do milho nos Estados Unidos e na China é em torno de $150 \mathrm{~kg} \mathrm{ha}^{-1}$ e $130 \mathrm{~kg} \mathrm{ha}^{-1}$, respectivamente, enquanto no Brasil a quantidade fica próxima a $60 \mathrm{~kg} \mathrm{ha}^{-1}$ (IFIA 2016).

As plantas absorvem o $\mathrm{N}$ na forma nítrica $\left(\mathrm{NO}_{3}{ }^{-}\right)$e/ou amoniacal $\left(\mathrm{NH}_{4}{ }^{+}\right)$, porém, no solo predomina a forma orgânica (mais de $95 \%$ do $\mathrm{N}$ total), que está presente na matéria orgânica como constituinte de 
diferentes moléculas com variados graus de recalcitrância, ou ainda como parte de organismos vivos, logo, as frações inorgânicas, compostas por $\mathrm{NO}_{3}{ }^{-}, \mathrm{NH}_{4}{ }^{+}$e nitrito $\left(\mathrm{NO}_{2}{ }^{-}\right)$estão presentes em pequenas concentrações (CANTERELLA 2007). Dessa forma, uma maneira de melhor aproveitar o $\mathrm{N}$ aplicado, é sua utilização na cultura antecessora, resultando em efeitos residuais com incrementos na cultura principal. A adubação nitrogenada, num sistema de integração lavoura-pecuária (ILP), com gramíneas de inverno antecedendo culturas de grãos, mostra-se como alternativa ao melhor aproveitamento do $\mathrm{N}$ (NOVAKOWISKI et al. 2011). Assim, a cultura do milho se destaca na ILP em virtude de seu alto potencial produtivo (VILELA et al. 2011) e elevada responsividade ao $\mathrm{N}$ aplicado e ao $\mathrm{N}$ residual da pastagem (SILVEIRA et al. 2012).

Os benefícios da adoção de sistemas integrados de produção, como a ILP, por exemplo, estão associados ao uso alternado do solo entre lavoura e pecuária, tanto no tempo quanto no espaço. Neste modelo de exploração, o sinergismo entre pastagens e culturas anuais resulta em melhorias das propriedades físicas, químicas e biológicas do solo. Além disso, favorece a quebra de ciclo de doenças e redução de insetos-pragas e de plantas daninhas, redução de riscos econômicos pela diversificação de atividades e redução de custo na recuperação e na renovação de pastagens em processo de degradação (VILELA et al. 2011). Porém, ASSMANN et al. (2010) ao estudar a produção de gado de corte sob pastagem de aveia em sistema de ILP concluíram que o não atendimento da demanda de $\mathrm{N}$ pode levar, a médio e longo prazo, à degradação do solo e do sistema.

Nos últimos anos tem se percebido uma redução na área de pastagens naturais e aumento na área de pastagens plantadas em Santa Catarina, SC, tal fato está relacionado com a melhoria dos sistemas de produção da pecuária leiteira e de corte, que tem optado pelo plantio de espécies forrageiras mais produtivas (EPAGRI/CEPA 2018). Nesse sentido, SC se destaca na produção de leite, sendo o quarto maior produtor do Brasil, atingindo a produção de 2.970.654 litros em 2018 (IBGE 2019). Recentemente uma nova modalidade de produção tem crescido nas propriedades leiteiras do estado, denominados Free Stall e Compost barns, nos quais os animais permanecem estabulados permanentemente, recebendo água e alimentação na instalação (JOCHIMS et al. 2016). Assim, nessa nova forma de produção integrada da propriedade rural, o rebanho leiteiro, deixa de pastejar a área, recebendo o pasto diretamente no coxo. Nesse sentido busca-se entender a dinâmica do $\mathrm{N}$ nessa nova abordagem, onde ocorre uma mudança na disponibilidade do nutriente, dependendo do manejo adotado no inverno, podendo aumentar ou diminuir sua disponibilidade para as plantas.

Diante do exposto, este estudo teve como objetivo avaliar o crescimento e a produtividade, bem como o aspecto econômico da cultura do milho, em resposta às doses de $\mathrm{N}$ em sistema integrado de produção.

\section{MATERIAL E MÉTODOS}

O experimento foi conduzido na Fazenda Experimental da UFSC, Campus de Curitibanos, na safra 2013/14. A área está situada a $27^{\circ} 16^{\prime} 26^{\prime \prime}$ de latitude Sul e $50^{\circ} 30^{\prime} 14^{\prime \prime}$ de longitude Oeste, e apresenta altitude média em relação ao nível do mar de $1.000 \mathrm{~m}$. O clima da região é classificado como temperado (mesotérmico úmido e verão ameno), segundo classificação de Köeppen. A precipitação média anual varia de 1500 a $1700 \mathrm{~mm}$, com temperatura média anual de $17^{\circ} \mathrm{C}$. Os dados de temperatura e precipitação durante o período de condução do experimento são apresentados na Figura 1.

O solo da área experimental é classificado como CAMBISSOLO HÁPLICO típico (SANTOS et al. 2013a), de textura argilosa (550 $\mathrm{g} \mathrm{kg}^{-1}$ de argila na camada superficial). Antes da implantação do experimento, o solo apresentou as seguintes características químicas na profundidade de 0,00-0,20 m: $36,19 \mathrm{~g} \mathrm{dm}^{-3}$ de matéria orgânica; $10,70 \mathrm{mg} \mathrm{dm}^{-3}$ de fósforo; $0,10 \mathrm{cmol}_{\mathrm{c}} \mathrm{dm}^{-3}$ de potássio; $6,00 \mathrm{pH}$ (em $\mathrm{CaCl}_{2}$ ).

O delineamento experimental utilizado foi o de blocos completos com tratamentos ao acaso com quatro repetições. Foram utilizadas quatro doses de N: 0, 40, 80 e $120 \mathrm{~kg} \mathrm{ha}^{-1}$, utilizando a ureia como fonte ( $45 \%$ de N). Cada parcela foi constituída por $5 \mathrm{~m}$ de largura e $12 \mathrm{~m}$ de comprimento $\left(60 \mathrm{~m}^{2}\right)$.

No inverno foi cultivado o consórcio de aveia preta (IPR 21) (Avena strigosa) e azevém comum (Lollium multiflorum), em uma densidade de 100 e $40 \mathrm{~kg}$ de sementes ha ${ }^{-1}$, respectivamente, e espaçamento entrelinhas de $0,17 \mathrm{~m}$. Foram realizados dois cortes durante o cultivo da pastagem de inverno, a qual foi roçada na altura de $10 \mathrm{~cm}$, para simular o pastejo, sendo toda a massa cortada retirada das parcelas. As parcelas de inverno receberam os mesmos tratamentos de adubação nitrogenada que os aplicados no cultivo de verão, sendo a aplicação de $\mathrm{N}$ efetuada parcelada, após a emergência e 30 dias após a primeira aplicação do N.

Tanto o cultivo de inverno quanto o de verão foram conduzidos em sistema de semeadura direta. A 
semeadura do milho foi realizada sob a palhada de inverno em 11 de outubro de 2013. Foi utilizado o híbrido simples Dekalb $245 \mathrm{PRO}^{\mathrm{TM}}$ na densidade de 65.000 sementes $^{-1} \mathrm{e}^{-1}$ com espaçamento entrelinhas de $0,7 \mathrm{~m}$. Na semeadura do milho foram utilizados $400 \mathrm{~kg} \mathrm{ha}^{-1}$ do adubo formulado 00-20-20 (N-P-K). A adubação nitrogenada de cobertura foi realizada a lanço, com um terço da dose na emergência e o restante quando $75 \%$ das plantas encontravam-se entre os estádios V4. Os tratos culturais e o manejo fitossanitário seguiram as recomendações técnicas para a cultura na região.

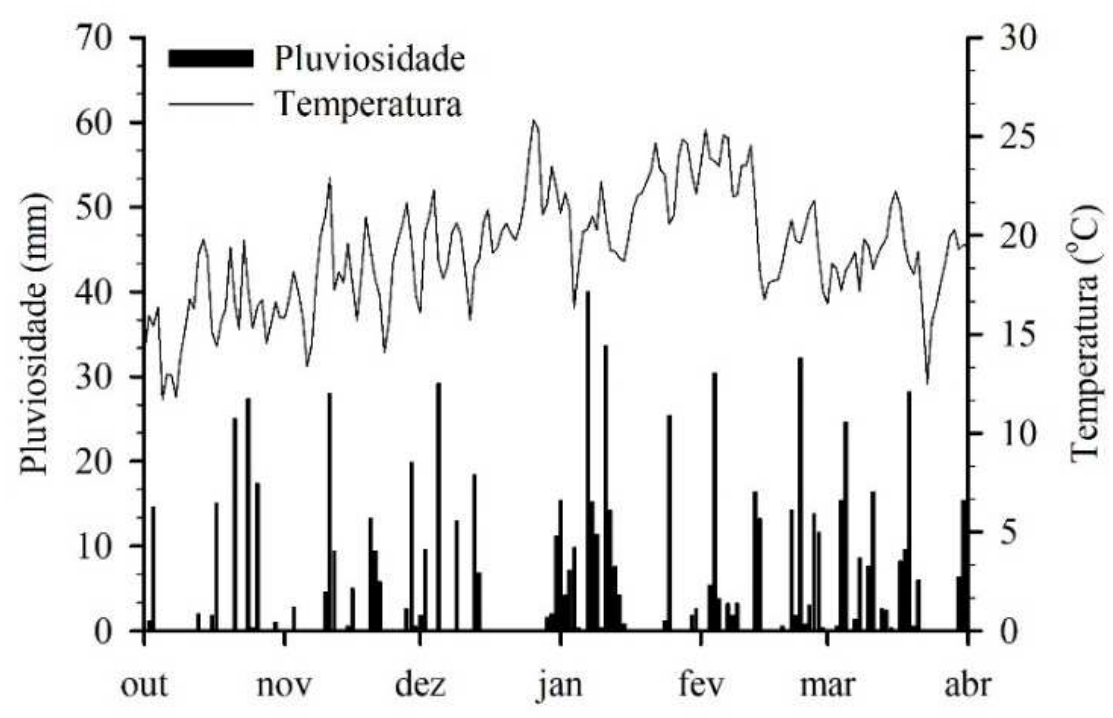

Figura 1. Temperatura média do ar $\left({ }^{\circ} \mathrm{C}\right)$ e pluviosidade $(\mathrm{mm})$ durante o período de condução do experimento. Curitibanos. SC. Fonte: INMET.

Figure 1. Mean air temperature $\left.{ }^{\circ} \mathrm{C}\right)$ and rainfall $(\mathrm{mm})$ during the experiment conduction period. Curitibanos. SC. Source: INMET.

Os componentes morfológicos de plantas de milho foram avaliados no estágio de grão úmido (R5), em 10 plantas na área útil da parcela, nas quais foram determinadas a altura de planta, diâmetro do colmo e altura de inserção da espiga principal. Os componentes da produção foram avaliados no estádio de maturação fisiológica das plantas (R6), onde se determinou o comprimento de espiga, número de fileiras por espiga, número de grãos por fileira, número de grãos por espiga e massa de mil grãos. Para estas estimativas utilizaram-se 10 espigas coletadas ao acaso na área útil da parcela. A produtividade de grãos foi estimada no restante da parcela útil, corrigindo-se a umidade para $14 \%$.

Para a análise econômica foi considerado o valor de $R \$ 65,00$ para saca de $50 \mathrm{~kg}$ de ureia considerando-se os valores médios praticados em outubro de 2013 na cidade de Curitibanos, SC. O preço de venda, considerado para a saca de grãos de $60 \mathrm{~kg}$, foi de $\mathrm{R} \$ 23,35$, a partir do valor médio da saca nos últimos cinco anos para e região.

Inicialmente os dados obtidos foram testados quanto a normalidade dos erros e homocedasticidade das variâncias pelo teste de Shapiro-Wilk e Bartlett, respectivamente. Posteriormente foram submetidos à análise de variância pelo teste $F(p<0,05)$, sendo efetuada análise de regressão, testando-se os modelos polinomiais de primeiro e segundo grau, bem como verificada a significância dos betas pelo teste $T$. Também se realizou a análise de correlação de Pearson entre as variáveis respostas avaliadas.

\section{RESULTADOS E DISCUSSÃO}

Todas as variáveis resposta foram influenciadas pelas doses de $N(p<0,05)$. Para o diâmetro do colmo e altura de inserção da espiga houve ajuste do modelo linear crescente, evidenciando o efeito positivo do $\mathrm{N}$ sobre parâmetros que compõem o crescimento da cultura do milho (Figura 2A e 2B). Todavia, para a altura de planta, o modelo significativo que melhor exemplificou a relação com às doses de $\mathrm{N}$, foi o modelo quadrático com ponto de máxima estimado na dose de $81 \mathrm{~kg} \mathrm{ha}^{-1}$ de $\mathrm{N}$, correspondente à uma altura de planta de 2,09 $\mathrm{m}$ (Figura $2 \mathrm{C}$ ).

GOES et al. (2013) avaliaram características agronômicas e produtividade do milho em função de doses de $\mathrm{N}$ em cobertura no inverno, verificaram que a altura de plantas e diâmetro de colmo ajustaram-se de maneira quadrática às doses aplicadas, com ponto de máximo estimado nas doses 105 e $84,4 \mathrm{~kg} \mathrm{ha}^{-1}$ de $\mathrm{N}$, respectivamente. A maior altura de inserção da espiga, segundo os autores, foi obtida com $85 \mathrm{~kg} \mathrm{ha}^{-1} \mathrm{de}$ 
N. Os valores de altura de planta e inserção de espiga apresentaram-se próximos aos encontrados no presente trabalho. Ocorre que o $\mathrm{N}$ maximiza o processo fotossintético, aumentando a divisão e expansão celular contribuindo para o aumento das variáveis que compõem o crescimento da planta.
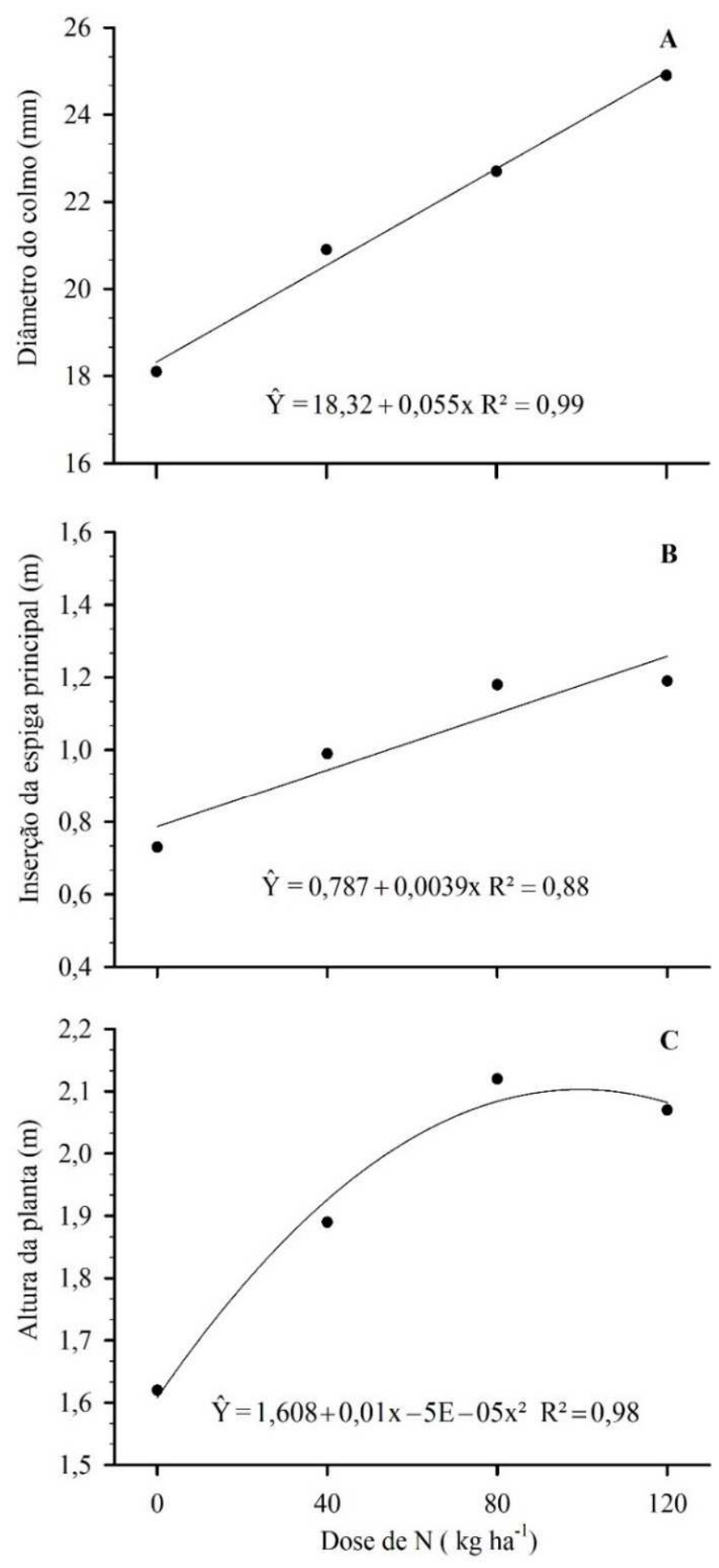

Figura 2. Diâmetro do colmo (A), altura de inserção da espiga (B) e altura de planta (C), da cultura do milho manejadas com doses de nitrogênio em sistema integrado de produção.

Figure 2. Stem diameter $(A)$, main ear insertion height $(B)$ and plant height $(C)$, of maize managed with nitrogen rates in integrated production system.

Em relação aos caracteres da espiga, houve ajuste do modelo linear para todas as variáveis, exceto para o número de fileiras por espiga, que apresentou comportamento quadrático com ponto de máximo estimado na dose de $80 \mathrm{~kg} \mathrm{ha}^{-1} \mathrm{~N}$ (Figura 3B). Resultados que vão ao encontro de GOES et al. (2013) que também observaram comportamento quadrático sobre o número de fileiras por espiga, porém, com ponto de máxima eficiência na dose de $103,5 \mathrm{~kg} \mathrm{ha}^{-1} \mathrm{~N}$. 

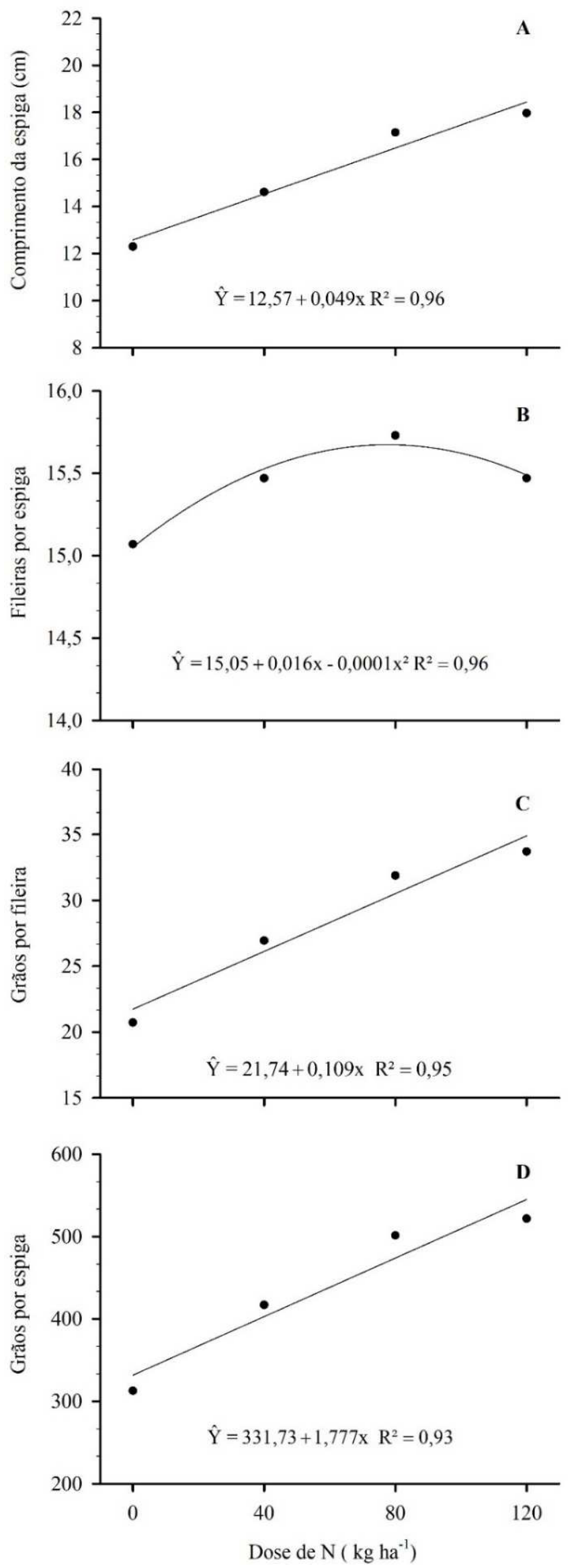

Figura 3. Comprimento da espiga (A), número de fileiras por espiga (B), número de grãos por fileira (C) e de grãos por espiga (D) da cultura do milho manejada com doses de nitrogênio em sistema integrado de produção.

Figure 3. Ear length $(A)$, number of rows per ear $(B)$, number of grains per row $(C)$ and grains per ear $(D)$ of maize managed with nitrogen rates in integrated production system. 
As variáveis, comprimento da espiga e grãos por fileira, apresentaram coeficiente angular de 0,049 e 0,109 para cada $1 \mathrm{~kg}$ de $\mathrm{N} \mathrm{ha}^{-1}$ aplicado, respectivamente, denotando o efeito positivo do $\mathrm{N}$ sobre essas variáveis para esse sistema de produção (Figura $3 \mathrm{~A}$ e $3 \mathrm{C}$ ). Nas mesmas condições de clima e solo do presente estudo, BESEN et al. (2018) também observaram que os componentes do rendimento, grãos por fileira, grãos por espiga e comprimento da espiga foram incrementados após aplicação de N, porém, os autores não observaram efeito no número de fileiras por espiga, em cultivo realizado sobre palhada de aveia.

De acordo com GOES et al. (2012) as características como comprimento de espiga são mais afetadas pelo genótipo do que pelas práticas culturais, enquanto o número de fileiras por espiga, número de grãos por fileira e número de grãos por espiga são afetados pela aplicação de N. Contudo, FERNANDES et al. (2005) não observaram efeito das doses de $\mathrm{N}\left(0,30,80\right.$ e $\left.190 \mathrm{~kg} \mathrm{ha}^{-1}\right)$ em relação ao número de fileiras por espiga, número de grãos por fileira e comprimento de espiga. Os valores de número de grãos por fileira e número de fileiras encontrados no presente estudo ficaram próximos aos encontrados por GOES et al. (2013). É válido ressaltar que pode ter ocorrido um efeito residual do $\mathrm{N}$ aplicado na pastagem durante o período do inverno, que favoreceram os caracteres avaliados.

A massa de mil grãos de milho esteve estreitamente relacionada $\left(R^{2}=0,98\right)$ com o aumento das doses de $\mathrm{N}$ em cobertura (Figura 4A). Resultados semelhantes foram encontrados por SICHOCKI et al. (2014) e QUEIROZ et al. (2011). Estudando o cultivo de milho em sistema plantio direto de longa duração com alto potencial produtivo, CAIRES \& MILLA (2016) também observaram estreita relação das doses de N com a massa de mil grãos, com coeficiente de determinação $\left(R^{2}=0,97\right)$, muito próximo ao obtido no presente estudo. Já, GOES et al. (2012), não observaram efeito significativo para massa de mil grãos, o que pode ter sido afetado pelos baixos índices pluviométricos. Segundo CAIRES \& MILLA (2016) apesar da massa de mil grãos ser importante para definição da produtividade do milho, tal resposta pode variar com as condições experimentais, especialmente, aquelas de ordem edafoclimáticas.

Estudando estratégias de adubação nitrogenada para a cultura do milho cultivado em ILP com consórcio de aveia e azevém durante o inverno, sendo a área pastejada por ovinos, LOPES et al. (2017) observaram aumento quadrático da massa de mil grãos com aumento das doses de N. Tais resultados, assim como os observados no presente estudo, se devem ao fato de que com o fornecimento de doses mais altas de $\mathrm{N}$, as folhas mantêm-se fisiologicamente ativas por um período mais longo, prolongando o período de enchimento de grãos, com reflexos positivos na massa de grãos (SILVA et al. 2005b).

A produtividade foi influenciada de forma positiva com comportamento linear em função das doses de $N$ (Figura 4A), corroborando com dados encontrados por QUEIROZ et al. (2011). Além do elevado coeficiente de determinação $\left(R^{2}=0,97\right)$ observado para a produtividade em função das doses, outro ponto relevante é a magnitude do coeficiente angular $(71,8 \mathrm{~kg})$, denotando alta resposta ao $\mathrm{N}$ no sistema produtivo em questão. Os resultados evidenciam elevada eficiência agronômica de uso do nitrogênio (EAN), que quando calculada segundo BALIGAR et al. (1990) tem-se valores de EAN de 81, 87 e 69 para as doses de 40,80 e $120 \mathrm{~kg} \mathrm{ha}^{-1}$ de N, respectivamente.

Presume-se que a elevada resposta ao $\mathrm{N}$ seja decorrente do parcelamento da dose total, durante o verão, maximizando a eficiência do nutriente, aliada às doses aplicadas no inverno, indicando provável reciclagem do elemento nesse sistema produtivo. De acordo com HENTZ et al. (2014) a associação do sistema ILP com o sistema plantio direto possibilita elevar a entrada de resíduo vegetal pelo uso de culturas comerciais e pastagens, o que permite suportar maior estoque de $\mathrm{N}$, bem como carbono, especialmente na camada superficial do solo, comparativamente a sistemas de produção que não utilizam pastagens. Aliado a isso, a pastagem quando submetida a cortes, ocorre um estímulo ao crescimento radicular, melhorando a absorção e reciclagem de nutrientes e água no sistema.

$\mathrm{O}$ provável efeito residual do $\mathrm{N}$ aplicado na pastagem durante o inverno é reportado em outros trabalhos com ILP (LANG et al. 2011, SANDINI et al. 2011, SILVEIRA et al. 2012). Em condições de clima subtropical no Segundo planalto Paranaense, LANG et al. (2011) verificaram contribuição do N residual da pastagem sobre a cultura do milho, sendo que as maiores diferenças foram verificadas quando o milho não recebeu fertilização nitrogenada, cujo a resposta ao $\mathrm{N}$ residual proporcionou um aumento de $263 \%$, em detrimento do tratamento com pastejo sem N. Em estudo realizado em Guarapuava, SANDINI et al. (2011) também verificaram efeito residual do $\mathrm{N}$ aplicado no inverno sobre o consórcio aveia e azevém influenciando positivamente a cultura do milho. Os resultados evidenciam a reciclagem de $\mathrm{N}$ sobre ILP, sendo que em ambientes pastejados é possível obter elevados índices produtivos com menores doses de $\mathrm{N}$ (LANG et al. 2011) proporcionando benefícios no contexto ambiental e econômico.

SILVEIRA et al. (2012) encontraram valores médios de produtividade do milho em área com pastejo e 
sem pastejo de 10.070 e $9.600 \mathrm{~kg} \mathrm{ha}^{-1}$, respectivamente, valores muito próximos aos alcançados com a dose de $80 \mathrm{~kg} \mathrm{~N}^{-1}$ no presente estudo, e que demonstram que sistemas integrados, se corretamente manejados, são benéficos ao sistema de produção.
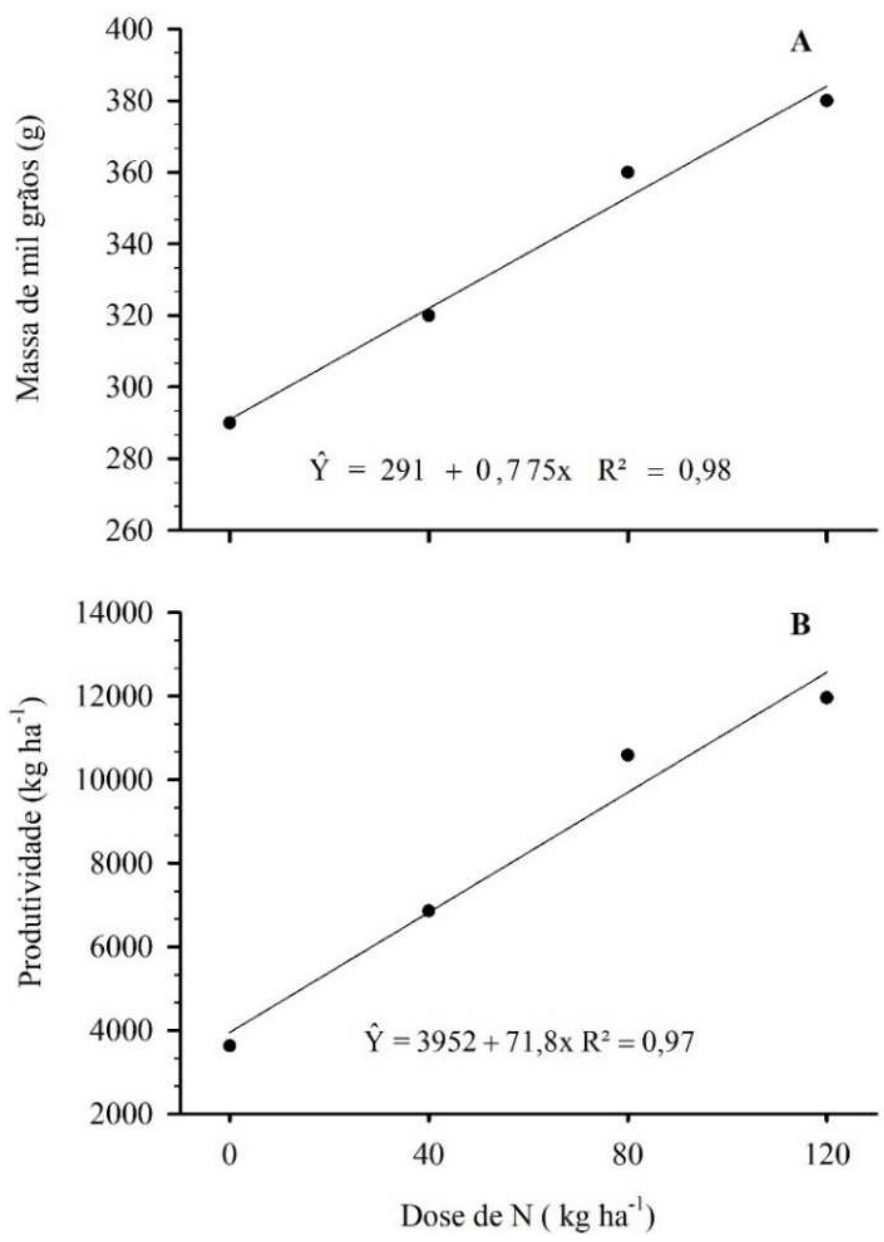

Figura 4. Massa de mil grãos (A) e produtividade (B) do milho manejada com doses de nitrogênio em sistema integrado de produção.

Figure 4. Mass of a thousand grains $(A)$ and grain yield $(B)$ of maize managed with nitrogen rates in integrated production system.

A produtividade média de milho obtida no estado de SC na safra 2013/14 situou-se em aproximadamente $7.385 \mathrm{~kg} \mathrm{ha}^{-1}$ de grãos (CONAB 2015), revelando que com $80 \mathrm{~kg}$ de N ha-1 no presente sistema produtivo foi possível aumentar em $3.201 \mathrm{~kg} \mathrm{ha}^{-1}$ o rendimento de grãos, comparativamente a média do estado. Embora, alguns produtores já tenham obtido produtividades superiores a $12.000 \mathrm{~kg} \mathrm{ha}^{-1} \mathrm{de}$ grãos de milho, enquanto outras médias bem inferiores, esse contraste se deve principalmente à diferença entre os sistemas de produção, evidenciando a necessidade de se conhecer dentro de cada sistema as doses de $\mathrm{N}$ que alcancem a máxima produção com menor custo.

ESCOSTEGUY et al. (1997) apontam que são necessários cerca de $20 \mathrm{~kg} \mathrm{ha}^{-1}$ de $\mathrm{N}$ para produção de $1.000 \mathrm{~kg} \mathrm{ha}^{-1}$ de grãos de milho. Desse modo para a produtividade das parcelas sem $\mathrm{N}$, as quais apresentaram rendimento médio de $3.630 \mathrm{~kg} \mathrm{ha}^{-1}$ estima-se que o solo foi capaz de suprir cerca de $73 \mathrm{~kg}$ ha $^{-1}$ de N, via mineralização da matéria orgânica do solo (MOS) durante o ciclo da cultura. Como o solo apresentava $36,9 \mathrm{~g} \mathrm{dm}^{-3}$ de $\mathrm{MO}$, ao considerarmos uma taxa de mineralização média da MOS de $3 \%$, teríamos a liberação de $107 \mathrm{~kg} \mathrm{ha}^{-1}$ de $\mathrm{N}$ ao ano. Considerando as maiores temperaturas e índices pluviométricos durante o cultivo de milho no verão é possível hipotetizar o aumento nas taxas de mineralização da MOS e consequente maior liberação de $\mathrm{N}$ durante a estação mais quente, em detrimento ao período mais frio do ano, contribuindo para a produtividade de grãos do milho.

Em relação à análise de correlação simples de Pearson, foi possível constatar que todas as variáveis respostas mensuradas se correlacionaram com o rendimento de grãos, exceto o número de fileiras por espiga (Tabela 1). Resultados que corroboram BESEN et al. (2018) nas mesmas condições de clima e solo do presente estudo. 
Tabela 1. Matriz de correlação de Pearson entre componentes morfológicos e do rendimento da cultura do milho: diâmetro do colmo (DC); altura de inserção de espiga (AIE); altura de planta (AP); fileiras por espiga (FE); grãos por fileira (GF); grãos por espiga (GE); comprimento de espiga (CE); massa de mil grãos (MMG) e produtividade (PROD).

Table 1. Pearson correlation matrix among morphological and yield parameters of maize: stem diameter $(D C)$; ear insertion height (AIE); plant height (AP); number of rows per ear (FE), number of grains per row (GF); grains per ear (GE); ear length (CE); mass of a thousand grains (MMG), and grain yield (PROD).

\begin{tabular}{lcclllllll}
\hline Variáveis & AIE & AP & FE & GF & GE & CE & MMG & PROD \\
\cline { 2 - 9 } DC & $0,95^{*}$ & $0,91^{*}$ & $0,72^{\text {ns }}$ & $0,98^{*}$ & $0,97^{*}$ & $0,98^{*}$ & $0,98^{*}$ & $0,98^{*}$ \\
AIE & & $0,99^{*}$ & $0,88^{\text {ns }}$ & $0,99^{*}$ & $0,99^{*}$ & $0,98^{*}$ & $0,96^{*}$ & $0,98^{*}$ \\
AP & & & $0,92^{\text {ns }}$ & $0,97^{*}$ & $0,98^{*}$ & $0,94^{*}$ & $0,94^{*}$ & $0,96^{*}$ \\
FE & & & & $0,83^{\text {ns }}$ & $0,85^{\text {ns }}$ & $0,80^{\text {ns }}$ & $0,75^{\text {ns }}$ & $0,78^{\text {ns }}$ \\
GF & & & & & $0,99^{*}$ & $0,99^{*}$ & $0,98^{*}$ & $0,99^{*}$ \\
GE & & & & & & $0,99^{*}$ & $0,98^{*}$ & $0,99^{*}$ \\
CE & & & & & & & $0,99^{*}$ & $0,99^{*}$ \\
MMG & & & & & & & & & $0,99^{*}$ \\
\hline
\end{tabular}

${ }^{*}$ Significativo à $5 \%$.

Enfatiza-se que entre as variáveis correlacionadas significativamente com o rendimento de grãos, todas apresentaram coeficientes de correlação maiores que 0,96 , denotando forte associação entre as variáveis. Em suma, percebe-se que todas as variáveis morfológicas e componentes de rendimento estiveram correlacionados entre si, com exceção do número de $\mathrm{FE}$, que não esteve associado a nenhuma variável resposta. Os resultados obtidos demonstram que a produtividade se correlaciona não somente com componentes do rendimento, mas também com parâmetros relacionados ao seu crescimento, tais como AIE, AP e DC.

Em relação à análise econômica (Tabela 2), observa-se que a dose de $120 \mathrm{~kg} \mathrm{ha}^{-1}$ resultou no maior acréscimo de lucro, quando comparada à testemunha. QUEIROZ et al. (2011) trabalharam com doses até $160 \mathrm{~kg} \mathrm{~N} \mathrm{ha}^{-1}$ em milho e concluíram que a dose de $120 \mathrm{~kg} \mathrm{ha}^{-1}$ foi a que proporcionou o melhor retorno econômico, indo ao encontro do observado no presente estudo. Em trabalho de SICHOCKI et al. (2014) a receita bruta e o lucro foram incrementados de forma linear com as doses de $\mathrm{N}(30,60,90,120$ e $150 \mathrm{~kg}$ $\mathrm{ha}^{-1}$ ) aplicadas.

Tabela 2. Análise econômica da aplicação de doses de nitrogênio na cultura do milho. Curitibanos, SC. Table 2. Economic analysis concerning the application of nitrogen rates in maize. Curitibanos, SC.

\begin{tabular}{cccccc}
\hline Doses de N & PROD & $\mathrm{RB}^{2 *}$ & $\begin{array}{c}\mathrm{CFN}^{3 *} \\
\text { - }\end{array}$ & Lucro & $\begin{array}{c}\text { Acréscimo } \\
\text { de lucro } \\
(\%)\end{array}$ \\
\hline 0 & $3.630,16$ & $1.412,74$ & 0 & $1.412,74$ & - \\
40 & $6.861,58$ & $2.670,30$ & 115,56 & $2.554,74$ & 80,84 \\
80 & 10.586 .44 & $4.119,89$ & 231,11 & $3.888,78$ & 175,27 \\
120 & $11.961,91$ & $4.655,18$ & 346,67 & $4.308,51$ & 204,98 \\
\hline
\end{tabular}

${ }^{1}$ Produtividade de milho; ${ }^{2}$ Renda bruta; ${ }^{3}$ Custo com fertilizante nitrogenado, ${ }^{*}$ Média de preço do milho praticado em Curitibanos, SC em março dos cinco últimos anos (R\$23,35 saca de $60 \mathrm{~kg}$ ). "(Fertilizantes comercializados em Curitibanos, SC, em novembro de 2013), utilizou-se ureia como fonte de $\mathrm{N}(\mathrm{R} \$ 65,00$ saca de $50 \mathrm{~kg}$ ).

O lucro de $\mathrm{R} \$ 4.308$ obtido com a dose de $120 \mathrm{~kg} \mathrm{~N} \mathrm{ha}^{-1}$, representa um acréscimo percentual no lucro de aproximadamente 205\% em relação a dose $0 \mathrm{~kg} \mathrm{~N}^{-1}$ (Tabela 2), demonstrando a importância do produtor investir na adubação nitrogenada. Considerando os valores atualizados (01/11/2019) pago pelo comércio local, tem-se o valor de $R \$ 40,00$ à saca de milho de $60 \mathrm{~kg}$, que condiz a uma receita bruta de $R \$$ 7.974 para a dose de $120 \mathrm{~kg} \mathrm{~N} \mathrm{ha}^{-1}$. Ao considerarmos o valor de $\mathrm{R} \$ 1.800$ à tonelada de ureia, tem-se uma despesa atual com fertilizantes nitrogenadas de $R \$ 133,266$ e 400, para as doses de 40, 80 e $120 \mathrm{~kg} \mathrm{~N}$ 
$h^{-1}$. Desse modo, num comparativo entre 2013 e 2019, os resultados apresentam a mesma tendência, sendo observado um acréscimo no lucro de $213 \%$ para a dose de $120 \mathrm{~kg} \mathrm{~N} \mathrm{ha}^{-1}$ em relação ao tratamento sem adubação nitrogenada.

Segundo CRUZ et al. (2008) a recomendação de adubação nitrogenada em cobertura no milho varia entre 60 a $100 \mathrm{~kg} \mathrm{ha}^{-1}$, mas na tomada de decisão sobre a adubação é necessário levar em consideração vários fatores, entre eles as condições edafoclimáticas, sistema de cultivo, época de semeadura, época e modo de aplicação e fonte de $\mathrm{N}$ utilizada, por isso a recomendação da adubação nitrogenada não deve ser generalizada. SILVA \& SOUZA (2007) encontraram a máxima eficiência econômica do milho em sucessão da aveia preta com a aplicação de $150 \mathrm{~kg} \mathrm{ha}^{-1}$ de $\mathrm{N}$ e a máxima eficiência técnica com a aplicação de 205 $\mathrm{kg} \mathrm{ha}^{-1}$ de N.

Avaliando indicadores de eficiência técnica e econômica do milho cultivado em sistema plantio direto no estado de Santa Catarina, SIMIONI et al. (2017) observaram que o menor custo de produção foi observado no manejo com integração lavoura-pecuária, em relação aos demais manejos. Nas mesmas condições de clima e solo do presente estudo, com uso exclusivo de adubo mineral, LOCATELLI et al. (2019) obtiveram lucro bruto parcial de $R \$ 7.142$ e 6.579 ha, mediante produtividade de 19.348 e $11.411 \mathrm{~kg}$ $\mathrm{ha}^{-1}$ de grãos de milho para as safras de 2014/15 e 2015/16, respectivamente. A variação do preço pago para saca de $60 \mathrm{~kg}$ de milho entre os anos ( $R \$ 24,24$ e 38,14 para 2014/15 e 2015/16, respectivamente) contribuiu para que a diferença de lucro não fosse tão expressiva, embora a diferença de rendimento entre os anos tenha sido de $7.937 \mathrm{~kg} \mathrm{ha}^{-1}$.

Em estudo realizado num Latossolo Vermelho Amarelo de textura Argilosa no estado de Minas Gerais, SANTOS et al. (2013b) reportaram incremento de $9,7 \mathrm{~kg}$ de grãos por $\mathrm{kg}$ de $\mathrm{N}$ aplicado, apresentando viabilidade econômica mesmo com a aplicação da maior dose avaliada (340 kg N ha ${ }^{-1}$ ). No presente estudo, houve incremento de $71,8 \mathrm{~kg}$ por $\mathrm{kg}$ de $\mathrm{N}$ aplicado, o que notavelmente contribuiu para os acréscimos observados na lucratividade, de tal modo que cada $1 \mathrm{~kg} \mathrm{~N}$ aplicado aumentou o lucro em 1,77\%. No trabalho de SANTOS et al. (2013b) as doses de máxima produtividade e de eficiência econômica foram

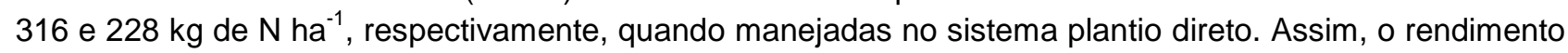
e o lucro podem ser ainda mais otimizados, visto que nas mesmas condições de clima e solo do presente estudo, BESEN et al. (2019) observaram resposta positiva da produtividade de grãos de milho até a dose de $300 \mathrm{~kg} \mathrm{ha}^{-1}$ de N, sendo que a cada $1 \mathrm{~kg}$ de $\mathrm{N}$ aplicado houve aumento do rendimento em $34 \mathrm{~kg} \mathrm{ha}^{-1}$.

No atual cenário vivenciado pelo setor produtivo, a perda da atratividade econômica da produção de milho pelos pequenos agricultores deve ser solucionada, buscando estratégias que otimizem o rendimento, sendo a adoção de sistemas que apresentem maior eficiência de produção essenciais para aumentar a competitividade da cultura e consequentemente aumentar a rentabilidade ao produtor.

Salienta-se também que em um sistema integrado a dinâmica do $\mathrm{N}$ tende a ser mais acelerada, favorecendo a cultura sucessora. Desta forma, o residual do $\mathrm{N}$ aplicado no inverno pode estar disponível por meio da mineralização da MOS para a cultura de verão, diminuindo assim, os níveis de $\mathrm{N}$ necessários via adubação para o milho, mantendo produtividades elevadas e consequentemente melhorando o sistema de produção.

\section{CONCLUSÃO}

O aumento das doses de nitrogênio influenciou positivamente todos os componentes morfológicos e de rendimento avaliados.

A produtividade de milho em sistema integrado de produção teve resposta linear positiva à aplicação de nitrogênio até $120 \mathrm{~kg} \mathrm{ha}^{-1}$.

Foi observada elevada eficiência de uso do nitrogênio, sendo que o aumento das doses maximizou a lucratividade, de tal modo que a maior dose $\left(120 \mathrm{~kg} \mathrm{~N} \mathrm{ha}^{-1}\right)$ aumentou o lucro em $205 \%$ comparativamente a ausência de adubação nitrogenada.

\section{REFERÊNCIAS}

ASSMANN TS et al. 2010. Produção de gado de corte e de pastagem de aveia em sistema de integração lavourapecuária em presença e ausência de trevo e nitrogênio. Revista Brasileira de Zootecnia 39: 1387-1397.

BALIGAR VC et al. 1990. Soil-plant interaction on nutrient efficiency plants: an overview. In: BALIGAR RV \& DUNCAN RR. (Ed). Crop as enhancers of nutrient use. San Diego: Academic. p.351-373.

BESEN MR et al. 2018. Fontes minerais de nitrogênio na sucessão milho-trigo em sistema de plantio direto. Journal of Agronomic Sciences 7: 87-102.

BESEN MR et al. 2019. Produtividade do milho em resposta à inoculação com Azospirillum brasilense e adubação nitrogenada em clima subtropical. Revista Brasileira de Milho e Sorgo 18: 219-230. 
CAIRES EF \& MILLA R. 2016. Adubação nitrogenada em cobertura para o cultivo de milho com alto potencial produtivo em sistema de plantio direto de longa duração. Bragantia 75: 87-95.

CANTERELLA H. 2007. Nitrogênio. In: NOVAIS RF et al. Fertilidade do solo. Viçosa: SBCS. p.375-470.

CONAB. 2015. Companhia Nacional de Abastecimento. Acompanhamento da safra brasileira de grãos. Brasília: Conab. $107 p$.

CRUZ JC et al. 2008. Cultivo do Milho. 4.ed. Sete Lagoas: Embrapa Milho e Sorgo. p.171-195.

EPAGRI/CEPA. 2018. Síntese Anual da Agricultura de Santa Catarina 2017-18. Florianópolis. Disponível em: http://webdoc.epagri.sc.gov.br/sintese.pdf. Acesso em: 04 nov. 2019.

ESCOSTEGUY PAV et al. 1997. Doses e épocas de aplicação de nitrogênio em cobertura na cultura do milho em duas épocas de semeadura. Revista Brasileira de Ciência do Solo 21: 71-77.

FERNANDES FCS et al. 2005. Dose, eficiência e uso de Nitrogênio por seis cultivares de milho. Revista Brasileira de Milho e Sorgo 4: 195-204.

GOES RJ et al. 2012. Nitrogênio em cobertura para o milho (Zea mays L.) em sistema plantio direto na safrinha. Revista Brasileira de Milho e Sorgo 11: 169-177.

GOES RJ et al. 2013. Características agronômicas e produtividade do milho sob fontes e doses de nitrogênio em cobertura no inverno. Revista Brasileira de Milho e Sorgo 12: 250-259.

HENTZ P et al. 2014. Ciclagem de Nitrogênio em Sistemas de Integração Lavoura-Pecuária. Ciência e Natura 36: 663676.

IBGE. 2019. Instituto Brasileiro de Geografia e Estatística Santa Catarina - Pecuária. Disponível em: https://cidades.ibge.gov.br/brasil/sc/pesquisa/18/0. Acesso em: 05 nov. 2019.

IFIA. 2016. International Fertilizer Industry Association. Fertilizer use by crop. 5.ed. Paris: IFA. Disponível em: http://www.fertilizer.org. Acesso em: 20 ago. 2018.

JOCHIMS F et al. 2016. O leite para o Oeste Catarinense. Agropecuária Catarinense 29: 18-21.

LANG CR et al. 2011. Integração Lavoura-Pecuária: eficiência de uso do nitrogênio na cultura do milho. Scientia Agraria 12: 53-60.

LOCATELLI JL et al. 2019. Uso de dejeto líquido de suínos permite reduzir a adubação mineral na cultura do milho? Revista de Ciências Agrárias 42: 628-637.

LOPES ECP et al. 2017. Estratégias de adubação nitrogenada na cultura do milho em sistema integrado de produção agropecuária. Revista Brasileira de Milho e Sorgo 16: 161-177.

NOVAKOWISKI JH et al. 2011. Efeito residual da adubação nitrogenada e inoculação de Azospirillum brasiliense na cultura do milho. Semina: Ciências Agrárias 32: 1687-1698.

QUEIROZ AM et al. 2011. Avaliação de diferentes fontes e doses de Nitrogênio na adubação da cultura do milho (Zea mays L.). Revista Brasileira de Milho e Sorgo 10: 257-266.

SANDINI IE et al. 2011. Efeito residual do nitrogênio na cultura do milho no sistema de integração lavoura-pecuária. Ciência Rural 41: 1315-1322.

SANTOS HG et al. 2013a. Sistema Brasileiro de Classificação de Solos. 3.ed. Brasília: Embrapa. 342p.

SANTOS LPD et al. 2013b. Doses de nitrogênio na cultura do milho para altas produtividades de grãos. Revista Brasileira de Milho e Sorgo 12: 270-279.

SICHOCKI D et al. 2014. Resposta do milho safrinha à doses de Nitrogênio e de Fósforo. Revista Brasileira de Milho e Sorgo 13: 48-58.

SILVA DA \& SOUZA LCF. 2007. Análise econômica de sucessões de culturas para milho, com níveis de nitrogênio em cobertura. Revista Brasileira de Milho e Sorgo 6: 256-262.

SILVA EC et al. 2005a. Doses e épocas de aplicação de nitrogênio na cultura do milho em plantio direto sobre Latossolo Vermelho. Revista Brasileira de Ciência do Solo 29: 353-362.

SILVA EC et al. 2005b. Épocas e formas de aplicação de nitrogênio no milho sob plantio direto em solo de cerrado. Revista Brasileira de Ciência do Solo 29: 725-733.

SILVEIRA ER et al. 2012. Grazing intensity and nitrogen in oat dry mass and yield of corn crop livestock systems. Semina: Ciências Agrárias 33: 1323-1331.

SIMIONI FJ et al. 2017. Indicadores de eficiência técnica e econômica do milho cultivado em sistema plantio direto no Estado de Santa Catarina, Brasil. Revista Ceres 64: 232-241.

VILELA L et al. 2011. Sistemas de integração lavoura-pecuária na região do Cerrado. Pesquisa Agropecuária Brasileira 46: 1127-1138. 